\title{
Influence of Submicron Fibrillated Cellulose Fibers from Cotton on Hydration and Microstructure of Portland Cement Paste
}

\author{
Jing Wu ${ }^{1, * D}$, Qingjun Ding ${ }^{2}$, Wen Yang ${ }^{3}$, Luoxin Wang ${ }^{1}$ and Hua Wang ${ }^{1}$ \\ 1 State Key Laboratory of New Textile Materials \& Advanced Processing Technology, College of Materials \\ Science and Engineering, Wuhan Textile University, Wuhan 430073, China; Wanglx@wtu.edu.cn (L.W.); \\ huawangabc@163.com (H.W.) \\ 2 State Key Laboratory of Silicate Materials for Architecture, College of Materials Science and Engineering, \\ Wuhan University of Technology, Wuhan 430070, China; dingqj@whut.edu.cn \\ 3 China West Construction Academy of Building Materials, Chengdu 610015, China; youngsun8228@163.com \\ * Correspondence: wujing313@whut.edu.cn
}

check for updates

Citation: Wu, J.; Ding, Q.; Yang, W.; Wang, L.; Wang, H. Influence of Submicron Fibrillated Cellulose Fibers from Cotton on Hydration and Microstructure of Portland Cement Paste. Molecules 2021, 26, 5831. https: //doi.org/10.3390/molecules26195831

Academic Editor: Peiyu Yan

Received: 26 July 2021

Accepted: 22 September 2021

Published: 26 September 2021

Publisher's Note: MDPI stays neutral with regard to jurisdictional claims in published maps and institutional affiliations.

Copyright: (c) 2021 by the authors. Licensee MDPI, Basel, Switzerland. This article is an open access article distributed under the terms and conditions of the Creative Commons Attribution (CC BY) license (https:// creativecommons.org/licenses/by/ $4.0 /)$.

\begin{abstract}
This paper reports the influence of submicron hydrophilic fibers on the hydration and microstructure of Portland cement paste. Submicron fibrillated cellulose (SMC) fibers was prepared by the acid hydrolysis of cotton fibers in $\mathrm{H}_{2} \mathrm{SO}_{4}$ solution $(55 \% v / v)$ for $1.5 \mathrm{~h}$ at a temperature of $50{ }^{\circ} \mathrm{C}$. The SMC fibers were added into cement with a dosage of $0.03 \mathrm{wt} . \%$, and the effect of SMC on the hydration and microstructure of cement paste was investigated by calorimeter analysis, XRD, FT-IR, DSC-TG, and SEM. Microcrystalline cellulose (MCC) fibers were used as the contrast admixture with the same dosage in this study. The results show that the addition of SMC fibers can accelerate the cement hydration rate during the first $20 \mathrm{~h}$ of the hydration process and improve the hydration process of cement paste in later stages. These results are because the scale of SMC fibers more closely matches the size of the C-S-H gel compared to MCC fibers, given that the primary role of the SMC is to provide potential heterogeneous nucleation sites for the hydration products, which is conducive to an accelerated and continuous hydration reaction. Furthermore, the induction and bridging effects of the SMC fibers make the cement paste microstructure more homogeneous and compact.
\end{abstract}

Keywords: cellulose fibers; submicron; cement paste; hydration; microstructure

\section{Introduction}

Concrete, one of the most widely used man-made materials, has a notoriously low tensile strength and strain capacity, with poor resistance to crack opening and propagation. Cracks can develop when concrete members deform under different degrees of external or internal strain. The driving forces for concrete cracking include the intrinsic contraction associated with cement hydration (such as autogenous shrinkage), plastic shrinkage induced by the exposed environment, and thermal shrinkage as a result of both factors [1,2]. Modern concrete becomes increasingly susceptible to cracking because of its generally higher cement content, reduced water-cementitious $(\mathrm{w} / \mathrm{cm})$ ratio, and pozzolanic mineral admixtures (such as slag cement) [3].

The incorporation of different types and sizes of fibers into cementitious composites is a common method to reduce the brittleness of the matrix and increase its durability, which is proportional to the resistance to crack propagation offered by the fibers bridging the matrix that effectively transfer the load [4].

The use of steel fibers makes the concrete members lighter by reducing their sectional dimension and improving their mechanical properties. However, after prolonged use, products made from steel fiber reinforced concrete (FRC) are known to develop cracks and lose their strength, mainly due to the steel's corrosion $[5,6]$. Furthermore, because of their 
large scale, steel fibers have no effect on the original defects that form during the hydration process of cement.

Synthetic fibers have been used with concrete to improve the cracking resistance, especially to reduce plastic shrinkage cracking $[7,8]$. However, the main issue with synthetic FRC is that the weak interface zone between the fibers and matrix due to the hydrophobicity of synthetic fibers decreases the toughening effect of synthetic fibers on concrete.

Due to their good thermal conductivity, low sensitivity, and high elastic modulus, carbon fibers have also been used in different types of concrete. Carbon fibers improve the flexural strength, toughness, splitting tensile strength, and cracking resistance of concrete [9-11]. However, their use frequently involves higher costs and greater energy consumption during the processing of fiber-reinforced cementitious composites.

When compared to the above fibers, cellulose fibers provide many advantages, including their wide availability, renewability, low density, relatively low cost, biodegradability, adequate stiffness and strength, surface roughness, as well as high specific hydrophilicity [12]. The high hydrophilicity and hygroscopicity of cellulose fibers can be attributed to the hydroxyl groups in the cellulose molecular structure, which results in good compatibility between cellulose fibers and cementitious materials [13]. Thus, cellulose fibers have been widely used as alternatives for conventional reinforcement within concrete. It has also been reported that the ductility and strength of cement concrete were markedly improved by using fibers of sisal [14], bagasse [15], jute [16], coconut [17], bamboo [18], fique [19], hemp [20], as well as flax [21] as reinforcing agents [22].

Despite these advancements, there are still several shortcomings that prevent the wider use of natural cellulose chopped fibers in reinforced cementitious materials for engineering: (1) The durability of cellulose fibers in the alkaline cement matrix is a major obstacle that needs to be overcome before the extensive application of cellulose fibers in reinforced cementitious materials can occur, given that the strength of fibers embedded in a cement matrix deteriorates with age [17,23]; (2) Wet swelling and dry shrinkage result in a significant decrease in the fibers' mechanical properties and an increase in the porosity of the cement matrix [24,25]; (3) It is difficult to achieve homogeneous dispersion of fibers in a concrete matrix [24-27].

Microcrystalline cellulose (MCC) [28] fibers or particles and nanocrystal cellulose (NCC) [29] are typically prepared from natural cellulose fibers by mechanical or chemical treatments, with the sugar, pectins, and hemicelluloses removed. Therefore, the use of these materials can potentially overcome the previously mentioned shortcomings of natural fiber. They have been used in cementitious composites to enhance the compressive and flexural strength [30-33], to increase the degree of cement's hydration [32,34-38] and to mitigate chloride-ion ingress [39]. MCC fibers modified with tetraethyl orthosilicate have been added to cementitious composites to act as a pozzolans, generating additional C-S-H linkages [40]. NCC has been shown to improve the flexural strength of cement composites due to an increase in the degree of hydration, which is possibly aided by a mechanism referred to as short-circuit diffusion [41]. As submicron fibrillated cellulose (SMC) fibers have a size scale just between that of MCC and NCC, their scale matches the size of cement hydration products, which allows them to induce the microstructure formation of cementitious paste, instead of reinforcing and diffusing. Given the primary role of SMC in Portland cement paste systems, we hypothesize that they: (1) provide potential heterogeneous nucleation sites for hydration products; (2) induce cement hydration products to grow on, along and finally embed SMC fibers; and (3) act as a bridge between cement particles.

In this experiment, the SMC fibers were prepared by the sulfuric acid hydrolysis of cotton, and then added into cement paste to induce the growth of calcium silicate hydrates in order to obtain more homogeneous and uniform microstructures. MCC fibers were used as the contrast admixture. The effect of SMC and MCC fibers on the microstructure and hydration of cement paste was investigated using calorimetry, FT-IR spectroscopy, XRD, TG-DSC, 29Si MAS-NMR, and scanning electron microscopy (SEM). From the results of 
these analyses, the role of SMC fibers on the hydration process and the microstructure evolution of cement paste is discussed.

\section{Experiment}

\subsection{Materials}

Cotton was used to prepare the SMC fibers. Cellulose microcrystalline (MCC) provided by Shanghai Hushi, Inc. (Shanghai, China) was used as the contrast admixture in this study. Figure 1 shows the SEM image of the cotton fibers and MCC fibers. Concentrated sulfuric acid $(98 \% v / v)$ and sodium bicarbonate were purchased from Shanghai Hushi, Inc. Deionized water was used in all experiments. For preparing the cement paste, ordinary Portland cement (OPC) CEM I 42.5, produced by Huaxin cement Co. Ltd. (Wuhan, China), was used with a Blaine fineness of $360 \mathrm{~m}^{2} / \mathrm{kg}$. Its chemical composition, physical and mechanical properties are shown in Table 1.
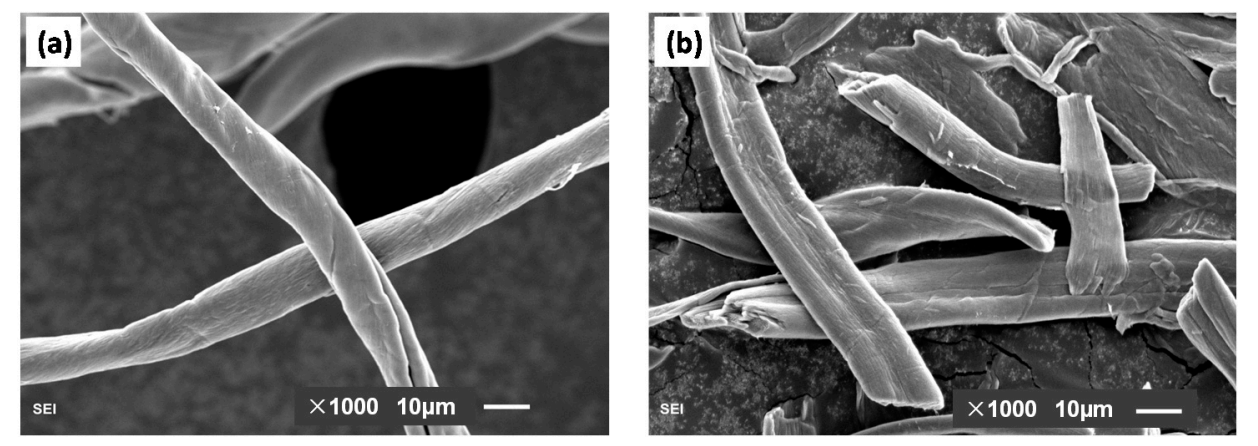

Figure 1. SEM image of (a) cotton fibers and (b) MCC fibers.

Table 1. Chemical composition, physical and mechanical properties of Portland cement used.

\begin{tabular}{cccc}
\hline Compound & Mass wt./\% & Physical Properties & \\
\hline $\mathrm{SiO}_{2}$ & 21.70 & Starting set time & $130 \mathrm{~min}$ \\
$\mathrm{CaO}$ & 63.01 & Ending set time & $210 \mathrm{~min}$ \\
$\mathrm{Al}_{2} \mathrm{O}_{3}$ & 4.76 & Surface density & $3.01 \mathrm{~g} / \mathrm{cm}^{3}$ \\
$\mathrm{Fe}_{2} \mathrm{O}_{3}$ & 3.57 & Blaine specific surface & $360 \mathrm{~m}^{2} / \mathrm{kg}$ \\
$\mathrm{MgO}$ & 2.12 & Compressive strength 3 day & $35 \mathrm{MPa}$ \\
$\mathrm{SO}_{3}$ & 1.98 & Compressive strength 28 day & $62 \mathrm{MPa}$ \\
Loss on ignition (LOI) & 3.5 & & \\
\hline
\end{tabular}

\subsection{Test and Instrumentation}

\subsubsection{Calorimeter Analysis}

A TAM Air isothermal microcalorimeter (NETZSCH, Selb, Germany) was used to measure the heat release rate of the hydrating specimens. The cement, SMC, and MCC were blended with deionized water externally for approximately $1 \mathrm{~min}$, after which the fresh pastes were placed into an airtight glass ampoule and inserted into the calorimeter. The experiment was carried out at a fixed temperature of $20^{\circ} \mathrm{C}$ over a period of $72 \mathrm{~h}$.

\subsubsection{FT-IR Characterization of Cement Paste}

FT-IR spectra were obtained using a JASCO 4100 FTIR spectrometer (JASCO, Tokyo, Japan). The solid pellet samples were prepared by mixing 2-3 $\mathrm{mg}$ of sample with $100 \mathrm{mg}$ of $\mathrm{KBr}$.

\subsubsection{XRD Analysis}

The diffractograms of the samples were determined using a Bruker D8 Advance XRD (Bruker, Berlin, Germany) device with a $\mathrm{Cu} \mathrm{k} \alpha \mathrm{X}$-ray source at $40 \mathrm{kV}$ and $40 \mathrm{~mA}$ (voltage and current, respectively). During data collection, the step-length was $0.02^{\circ}$, the scanning rate was $2^{\circ} / \mathrm{min}$ and the $2 \theta$ range was $5-60^{\circ}$. 


\subsubsection{DSC-TG Analysis}

Thermal analysis (DSC-TG) was conducted using a STA449F3 (NETZSCH, Selb, Germany) apparatus at a heating rate of $15^{\circ} \mathrm{C} / \mathrm{min}$ from $20^{\circ} \mathrm{C}$ to $1000{ }^{\circ} \mathrm{C}$ under a nitrogen atmosphere.

\subsubsection{Scanning Electron Microscopy (SEM)}

SEM (JEOL, Tokyo, Japan) was used to investigate the microstructural properties of the fibers and cement pastes and was performed using an FEI/Quanta450 FEG microscope in secondary electron imaging mode.

\subsection{Methods}

\subsubsection{Acid Hydrolysis of Cotton Fibers}

Cellulose fibers typically consist of microfibrils of macromolecules and contain two parts: amorphous regions and crystalline regions. After an acid treatment and high shear mechanical processing of natural cellulose fibers, the amorphous portion of the cotton fibers can be removed or eliminated, allowing submicron-scale SMC fibers that consist of crystalline regions to be prepared. Submicron fibrillated cellulose fibers from cotton can be obtained by optimizing acid hydrolysis process parameters, such as varying acid solution concentration, reaction temperature and time. The apparatus for preparation of SMC fibers is shown in Figure 2.

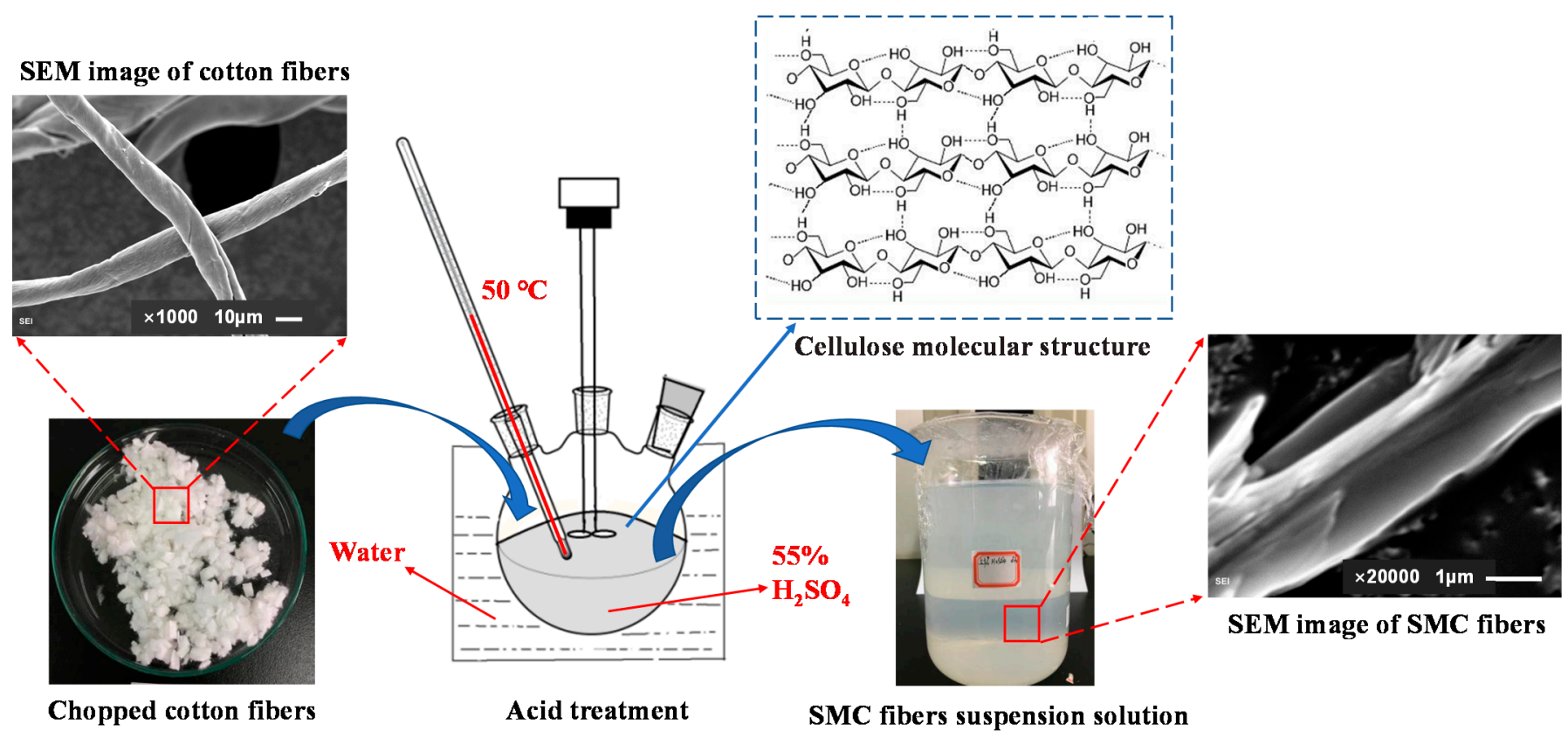

Figure 2. Apparatus for preparation of SMC fibers.

Cotton was added to $55 \%(w / w)$ sulfuric acid solution and then heated to $50{ }^{\circ} \mathrm{C}$ with stirring for $1.5 \mathrm{~h}$. After treatment with acid, the entire solution was transferred to a glass beaker containing a twentyfold excess volume of deionized water to terminate the reaction. This solution was kept still until the sediment settled to the bottom of the beaker. The solution supernatant was then removed, and an excess volume of deionized water was added to the beaker. A pH meter was used to measure the $\mathrm{pH}$ value of the solution until it was approximately 6.5. This solution was then centrifuged at $4000 \mathrm{rpm}$ to obtain a concentrated aqueous solution of suspended SMC fibers with a solid content of $12-13 \%$, which was used to prepare the samples. An SEM image of SMC is shown in Figure 2, showing that the diameter of the fibers is approximately $1 \mathrm{um}$. The scale of SMC fibers matches that of cement hydration products. 


\subsubsection{Preparation of Cement Pastes}

Mix proportions are listed in Table 2, and the water/binder ratio of the paste is 0.35 . Before the preparation of the mix, MCC and SMC fibers were added into the weighed deionized water and dispersed by ultrasonication, at the power of $325 \mathrm{~W}$ and frequency of $20 \mathrm{kHz}$, for $30 \mathrm{~min}$ to obtain uniform suspensions. Cement was added first to the mixing container, and then water containing the dispersed fibers was added into the dry cement and mixed for $3 \mathrm{~min}$ with a revolution speed of $60 \mathrm{r} / \mathrm{min}$, then for an additional $2 \mathrm{~min}$ with an increased revolution speed of $130 \mathrm{r} / \mathrm{min}$. The cement pastes were cured for 28 days according to GB/T17671-1999 [42], using standard curing conditions at a temperature of $20{ }^{\circ} \mathrm{C}$ with a relative humidity of $95-100 \%$. To prepare the samples for SEM, FTIR, XRD, DSC-TG, and NMR, small fragments obtained from the middle portion were placed into an ethyl alcohol solution for 10 days, then dried at $80^{\circ} \mathrm{C}$ for $8 \mathrm{~h}$.

Table 2. Cement pastes produced.

\begin{tabular}{cccc}
\hline Mixture Components/wt. $\%$ & Control & SMC & MCC \\
\hline Portland cement & 100 & 100 & 100 \\
Water & 35 & 35 & 35 \\
SMC, Submicron fibrillated cellulose fibers & None & 0.03 & None \\
MCC, Microcrystalline cellulose fibers & None & None & 0.03 \\
\hline
\end{tabular}

\section{Results and Discussion}

\subsection{Hydration Heat Evolution}

Figure 3 shows the changes in the hydration heat evolution rate of the control paste, the paste with MCC, and the paste with SMC. The acceleration period of each of the three pastes begins approximately $2 \mathrm{~h}$ after introduction of the water and ends at approximately $10 \mathrm{~h}$. The MCC and control paste curves are similar in shape, but the SMC curve paste is quite different because its shoulder peak is greater than its main peak. For the MCC paste, there is a tendency for the curve to shift to the right, and the heat evolution rate of the hydration peaks during the acceleration period is lower than the control paste. However, in the SMC paste, the heat evolution rate of the hydration peak is higher than that of the control paste.

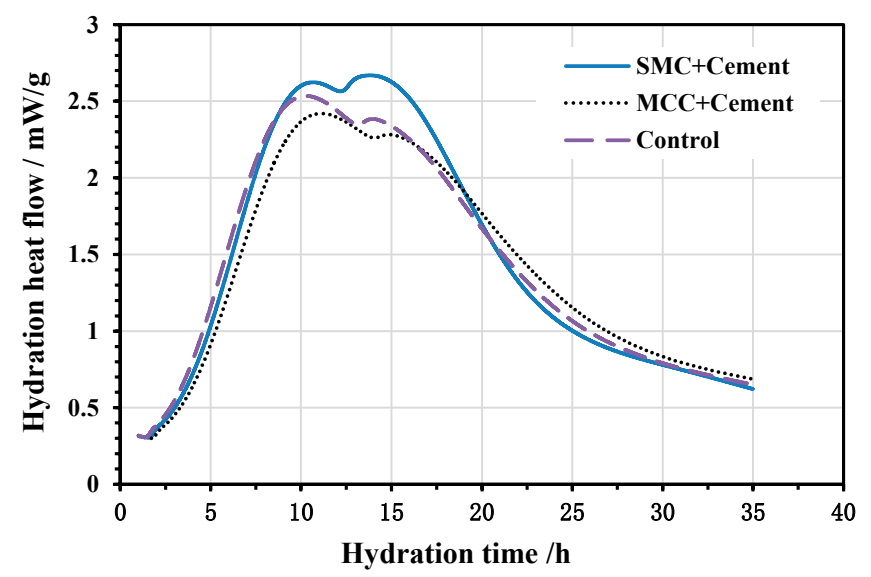

Figure 3. Hydration heat evolution rate curves of cement pastes.

Sneillings proposed [43] that the kinetics during the main heat evolution peak are controlled by the growth of C-S-H "needles", which grow from the surface of Portland cement grains once they are mixed with water. At the heat evolution peak, the surface is covered, but the deceleration is not attributed to diffusion control [44]. The shoulder peak comes from the renewed reaction of $\mathrm{C}_{3} \mathrm{~A}$ after depletion of sulfate in solution, but the release of sulfate absorbed onto C-S-H means that ettringite continues to form [45]. 
Quennoz and Scrivener [46] used in situ XRD to confirm that the formation of ettringite during the shoulder peak occurred around $15 \mathrm{~h}$.

From the results of the hydration heat tests, it can be observed that SMC fibers accelerate the reaction rate during the early hydration period. The reason for this phenomenon is that the primary role of the microscale fibers is to provide potential heterogeneous nucleation sites for the hydration products and to act as growth inducers for the microstructure of cement paste. In contrast, MCC seems to retard the hydration of the cement during the first $20 \mathrm{~h}$; the decrease in the hydration heat flow of sample "MCC+Cement" might be caused by decreasing the water-to-cement ratio because of moisture absorption by the MCC. The hydration heat flow of the MCC sample was higher than that of the SMC and control samples after $20 \mathrm{~h}$, because the water stored in MCC starts to participate in the hydration reaction. Iolanda A. [36] also investigated the effect of microcrystalline and microfibrillated cellulose on the hydration of cement pastes, indicating that the MCC act as water reservoirs. The lack of free water during the hydration process of MCC pastes causes them to release their previously retained water.

The accumulated heat curves of hydration for different pastes are shown in Figure 4, which shows the relationship between the accumulated heat evolution and the hydration time during 10 to $20 \mathrm{~h}$ (Figure $4 \mathrm{a}$ ) and the first $70 \mathrm{~h}$ (Figure $4 \mathrm{~b}$ ). In agreement with the exothermic rate trend, the addition of SMC led to only a slightly higher heat release, whereas that of MCC led to a lower heat release compared to the pure cement paste.

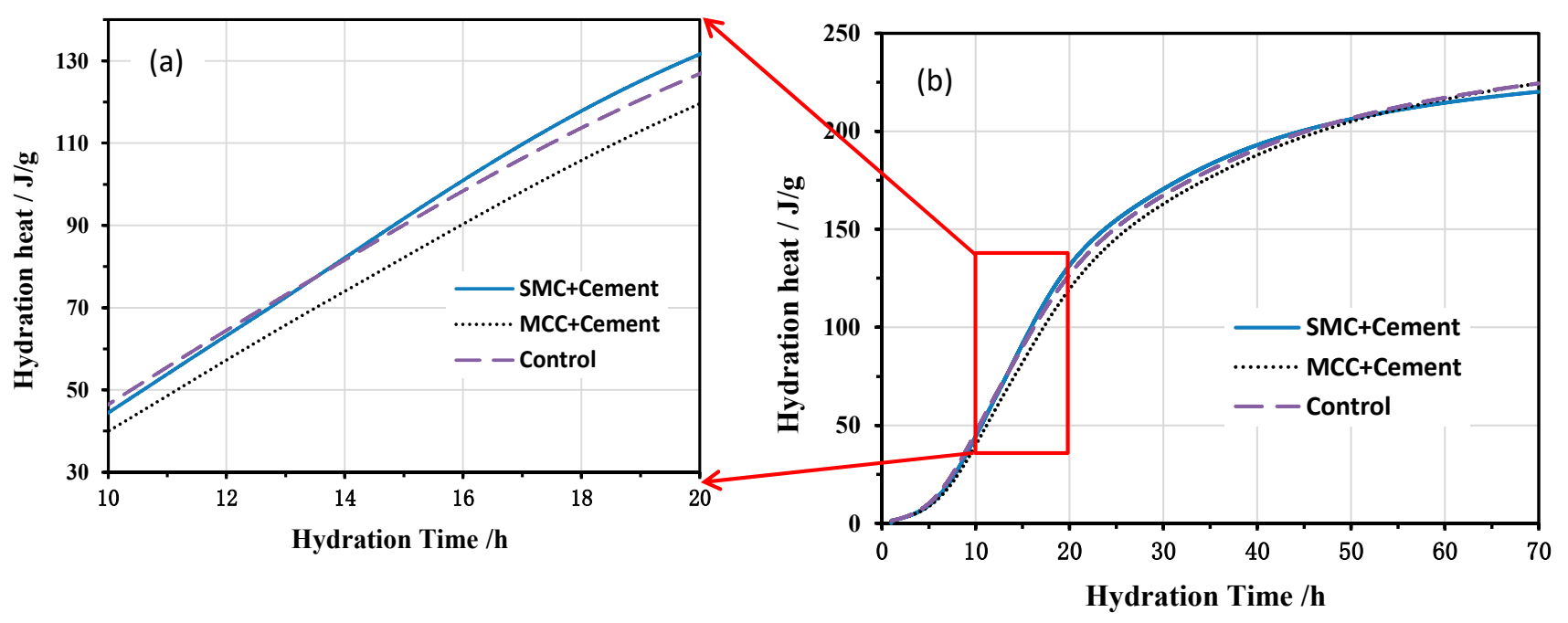

Figure 4. Accumulated heat of hydration for different pastes during (a) from 10 to $20 \mathrm{~h}$ and (b) the first $70 \mathrm{~h}$.

\subsection{FT-IR Analysis of the Hydrated Cement Pastes}

The FT-IR spectra of SMC and cement pastes with and without SMC at 3 days and 28 days are shown in Figure 5. The main absorption band and characteristic frequency of cellulose are $610-670,980-1060,1421,1650,2900,3200-3450 \mathrm{~cm}^{-1}$ [47]. The structure of the $\mathrm{SMC}$ is confirmed from the $\mathrm{O}-\mathrm{H}$ stretching vibration peak at $3350 \mathrm{~cm}^{-1}$, the $\mathrm{C}-\mathrm{H}$ vibration peak at $2900 \mathrm{~cm}^{-1}$ and the absorption peak of $-\mathrm{CH}_{2}$ on glucose at $1433 \mathrm{~cm}^{-1}$. The structure of the C-S-H gel is confirmed from the $\mathrm{SiO}_{4}{ }^{2-}$ stretching vibration peak at $1175-860 \mathrm{~cm}^{-1}$. The $\mathrm{Ca}(\mathrm{OH})_{2}$ is confirmed by the $\mathrm{O}-\mathrm{H}$ stretching vibration peak at $3600-3680 \mathrm{~cm}^{-1}$. The AFt and AFm are confirmed by the $\mathrm{SiO}_{4}{ }^{2-}$ stretching vibration peak at $1120 \mathrm{~cm}^{-1}$ and $3640 \mathrm{~cm}^{-1}$ respectively. Cement hydration gradually completes as its age increases, with the $\mathrm{AFt}\left(3 \mathrm{CaO} \cdot \mathrm{Al}_{2} \mathrm{O}_{3} \cdot 3 \mathrm{CaSO}_{4} \cdot 32 \mathrm{H}_{2} \mathrm{O}\right)$ in the cement hydration products transforming into AFm $\left(3 \mathrm{CaO} \cdot \mathrm{Al}_{2} \mathrm{O}_{3} \cdot \mathrm{CaSO}_{4} \cdot 12 \mathrm{H}_{2} \mathrm{O}\right)$. Therefore, the peak at $3640 \mathrm{~cm}^{-1}$ appears in the cement pastes without $\left(\mathrm{b}^{\prime}\right)$ and with $\left(\mathrm{c}^{\prime}\right)$ SMC fibers at 28 days, but the peak at $1120 \mathrm{~cm}^{-1}$ is weakened. 


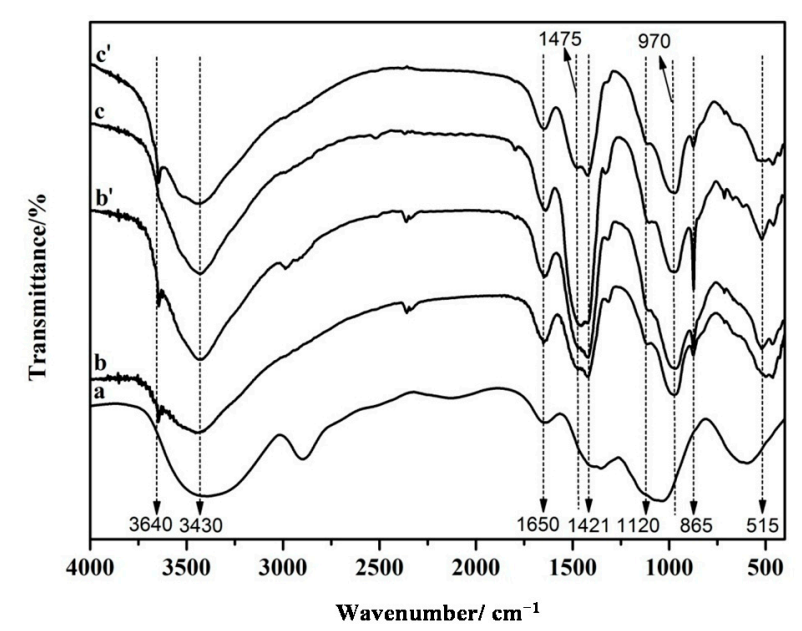

Figure 5. FT-IR spectra of (a) SMC, (b) cement paste at 3 days, (b') cement paste at 28 days, (c) cement paste with SMC at 3 days, and $\left(c^{\prime}\right)$ cement paste with SMC at 28 days.

\subsection{XRD Analysis of the Hydrated Cement Pastes}

The XRD patterns of different cement pastes at 3 and 28 days are shown in Figure 6. From Figure 6, no obvious new phase is found in the specimens doped with MCC and $\mathrm{SMC}$, and the curves of the control, MCC, and SMC pastes are almost identical at the same age. Results of the XRD analysis indicate the existence of alite $\left(C_{3} S\right)$, belite $\left(C_{2} S\right)$, calcium hydroxide $\left(\mathrm{Ca}(\mathrm{OH})_{2}, \mathrm{CH}\right)$, and ettringite $(\mathrm{AFt})$. The diffraction peaks of $\mathrm{C}_{3} \mathrm{~S}$ and $\mathrm{C}_{2} \mathrm{~S}$ in cement at an age of 3 days are still very strong, which indicates that there is some amount of the unhydrated $C_{3} S$ and $C_{2} S$ present at such an early age. It is worth noting that the diffraction peaks of $C_{3} S$ and $C_{2} S$ in the SMC sample at 28 days are weaker than that of the MCC sample at the same age. In contrast, it can be clearly seen from the XRD patterns that the diffraction peaks of $\mathrm{CH}$ in the SMC sample at 28 days was the strongest. It indicates that SMC contributed to accelerating the hydration of the cement component, which is reflected in the increase in the calcium hydroxide content of hydration products.

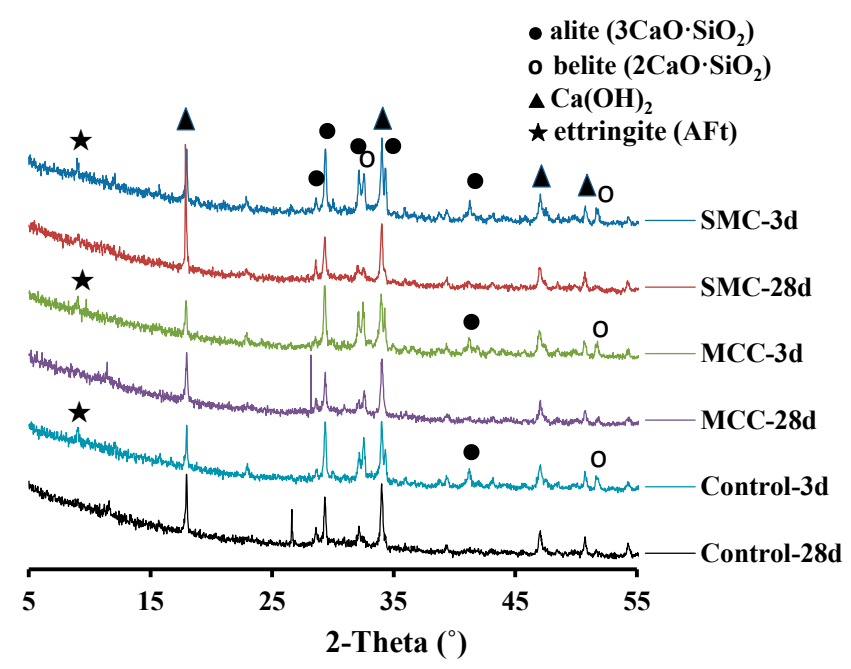

Figure 6. XRD patterns of cement pastes after 3 and 28 days of hydration.

The $\mathrm{CH}$ peak is the main performance index of cement paste specimens because the $\mathrm{CH}$ content in mixtures can be used to track changes in the amount of C-S-H. For the XRD analysis, the main characteristic peak of $\mathrm{CH}$ is located at $2 \theta=18.05^{\circ}$. Although there is no direct method to determine the concentration of $\mathrm{C}-\mathrm{S}-\mathrm{H}$, the $\mathrm{CH}$ content can indirectly determine the concentration of C-S-H. In order to further explore the reaction mechanism of the three cementitious systems, thermal analysis (TG-DSC) was used to calculate the $\mathrm{CH}$ amount in the hydration products. 


\subsection{Thermal Analysis of the Hydrated Cement Pastes}

The thermal analysis (DSC) of samples at 1 and 28 days are shown in Figure 7. The DSC results can be used to determine the crystallinity of $\mathrm{CH}$ and other hydrates (water loss), including C-S-H, AFt, gypsum, and others. For those aged 3 and 28 days, the DSC curve of pastes containing SMC were very similar to that of pastes containing MCC, but different from the control sample. After 28 days, the peak of the calcium hydroxide became higher and sharper.
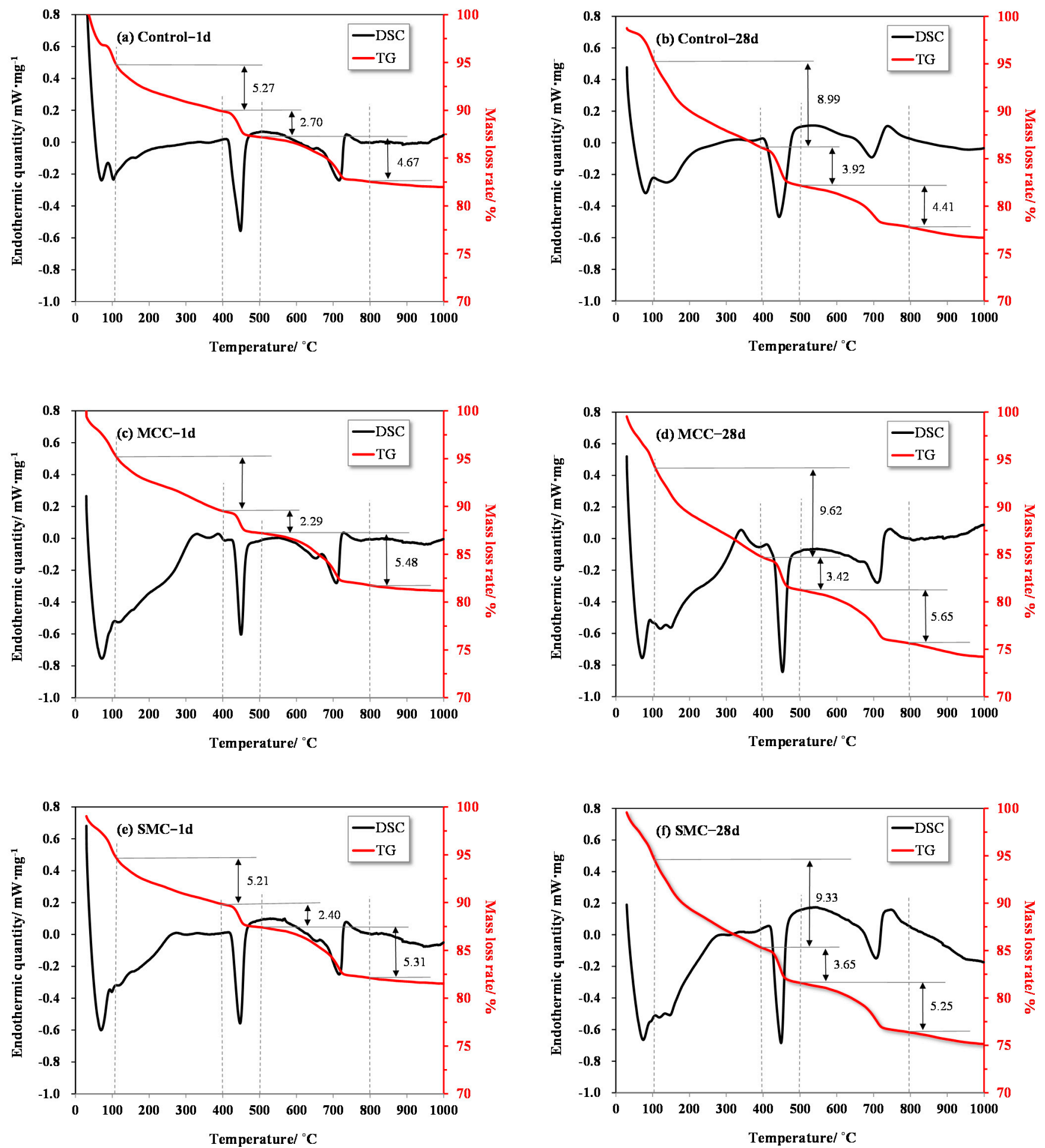

Figure 7. DSC analysis of control pastes and cement pastes with SMC and MCC fibers at the age of 1 day and 28 days. 
DSC curves exhibit four distinct stages in the decomposition of the control paste, the MCC cement paste and the paste with SMC fibers: (1) at temperatures between 20 and $105^{\circ} \mathrm{C}$, which is related to free water; (2) at temperatures between 105 and $400{ }^{\circ} \mathrm{C}$, which is related to the dehydration of C-S-H gel and decomposition of AFt, $\mathrm{AFm}$ and gypsum; (3) temperatures between 400 and $500{ }^{\circ} \mathrm{C}$, which correspond to the decomposition of $\mathrm{CH}$ (weight loss $L_{C H}$ ); (4) temperatures between 670 and $780{ }^{\circ} \mathrm{C}$, which correspond to the decomposition of $\mathrm{CaCO}_{3}$ (weight loss $L_{\text {Calcite }}$ [ [48].

For cement paste, the free water content $\left(W_{f}\right)$ and bound water content $\left(W_{b}\right.$, constitutive of C-S-H and AFt) make up the total water content, WT (Equation (1)). Moreover, the total water content $\left(W_{T}\right)$ is calculated as the total weight loss between 20 and $1000{ }^{\circ} \mathrm{C}\left(L_{T}\right)$, minus the weight losses due to the dehydroxylation of portlandite $\left(L_{C H}\right)$, the decarbonation of calcite $\left(L_{\text {Calcite }}\right)$, and the thermal decomposition of cellulose $\left(L_{\text {Cellulose }}\right)$ (Equation (2)). The above data can be obtained from the results of thermal analysis (TG), with the weight loss of cellulose from its content in cement paste $(0.03 \%$, Table 2$)$. Furthermore, the total $\mathrm{CH}$ content $\left(P_{T}\right)$ of each sample was evaluated using Equation (3). The thermogravimetric analysis results of samples are displayed in Table 3 , and the $\mathrm{CH}$ content results are shown in Figure 8.

$$
\begin{gathered}
W_{T}=W_{b}+W_{f} \\
W_{T}=L_{T}-L_{C H}-L_{\text {Calcite }}-L_{\text {Cellusose }} \\
P_{T}=74 / 18 \times L_{C H}+74 / 44 \times L_{\text {Calcite }}
\end{gathered}
$$

Table 3. The thermogravimetry results of samples.

\begin{tabular}{cccccccccc}
\hline Sample & $W_{f} / \%$ & $W_{b} / \%$ & $L_{C H} / \%$ & $L_{\text {Calcite }} / \%$ & $L_{\text {Cellulose }} / \%$ & $\boldsymbol{L}_{T} / \%$ & $\boldsymbol{W}_{T} / \%$ & $\begin{array}{c}\text { Percentage of } \\
\boldsymbol{W}_{b} / \boldsymbol{W}_{T} / \%\end{array}$ & $\begin{array}{c}\text { Portlandite } \\
\text { Content, } \boldsymbol{P}_{T} / \%\end{array}$ \\
\hline Control-1d & 4.88 & 5.74 & 2.70 & 2.64 & 0.03 & 18.02 & 12.65 & 61.42 & 15.54 \\
MCC-1d & 4.45 & 6.56 & 2.29 & 2.92 & 0.03 & 18.81 & 13.57 & 67.21 & 14.33 \\
SMC-1d & 4.00 & 6.73 & 2.40 & 2.81 & 0.03 & 18.47 & 13.23 & 69.77 & 14.59 \\
Control-28d & 3.63 & 11.36 & 3.92 & 2.22 & 0.03 & 23.34 & 17.17 & 78.86 & 19.85 \\
MCC-28d & 5.25 & 11.44 & 3.42 & 2.79 & 0.03 & 25.79 & 19.55 & 73.15 & 18.75 \\
SMC-28d & 4.99 & 10.94 & 3.65 & 3.02 & 0.03 & 24.86 & 18.16 & 72.47 & 20.08 \\
\hline
\end{tabular}

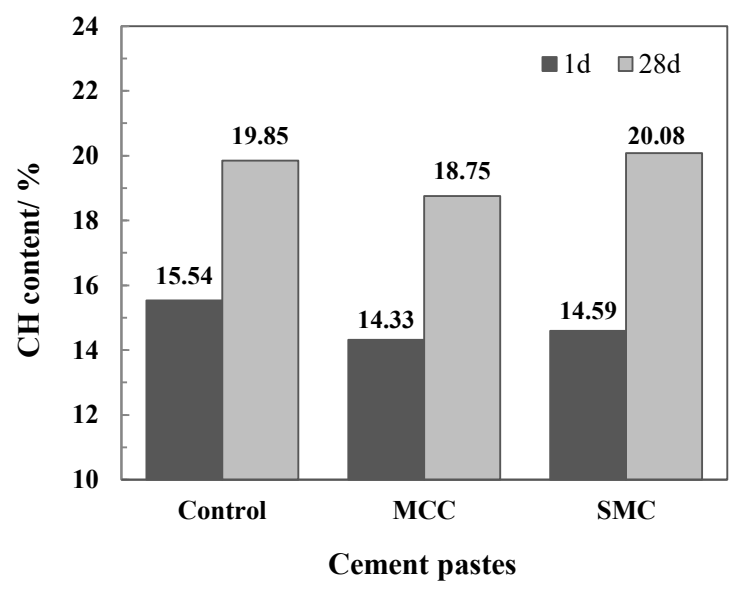

Figure 8. $\mathrm{CH}$ content in cement pastes at the age of 1 and 28 days.

As shown in Figure 8, the $\mathrm{CH}$ contents of the three systems at the age of 1 day are quite close, that of the control, MCC and SMC samples are 15.54, 14.33, and $14.59 \%$ respectively. At the age of 28 days, the $\mathrm{CH}$ contents of the control, MCC and SMC samples are 19.85, 18.75 , and $20.08 \%$ respectively. These results indicate that microscale cellulose fibers (MCC and $\mathrm{SMC}$ ) do not consume $\mathrm{CH}$, because there is no extra pozzolanic reaction caused by MCC and SMC. The SMC cement paste has the highest $\mathrm{CH}$ content. These results are in agreement with the analysis of this compound by XRD. It confirms that, compared with 
MCC, SMC is more conducive to promoting the hydration reaction of cement components, thereby improving the hydration degree of cement. Recent studies indicate that $\mathrm{CH}$ formed in pastes containing MCC are more crystalline [36].

\subsection{SEM}

At the early hydration stage, the C-S-H gel gathers around the original cement particles, with the needles on the individual gel clusters interweaving to form a porous structure where they contact one another $[49,50]$. The properties of high hydrophilicity of cellulose fibers can be attributed to the hydroxyl groups in the cellulose molecular structure, which bring about a good compatibility between cellulose fibers and cementitious materials. The hydration product C-S-H adheres to the surface of the MCC fiber. However, due to the large diameter and the internal empty cavity of MCC fiber, it absorbs water and swells in the early stages. As shown in Figure 9a, with the hydration of cement, the hollow MCC fiber constantly lose water and contract, resulting in gaps appearing around the cotton fiber at the age of 28 days. However, the matrix structure around the MCC is relatively dense.
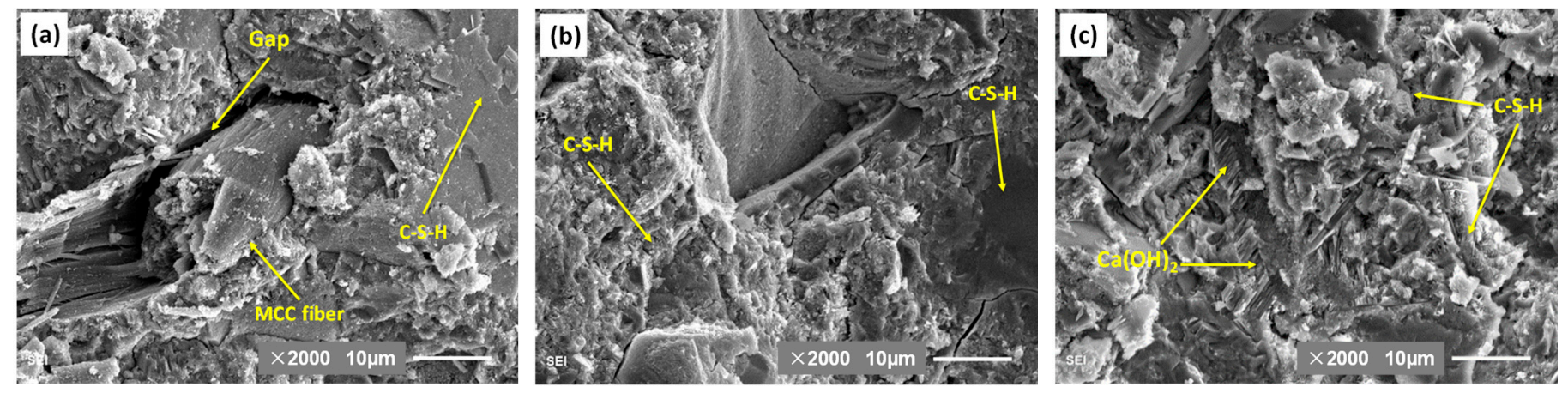

Figure 9. The SEM micrographs of cement paste with (a) MCC, (b) SMC, and (c) control sample at 28 days.

Figure $9 \mathrm{~b}$ shows the SEM micrographs of the SMC cement paste at 28 days. It is difficult to find the SMC contour, but the microstructure of cement paste with SMC is more compact and uniform than that of the MCC and control samples. In contrast, the SEM image in Figure 9c shows that the pure cement sample at 28 days has a non-uniform area of its porous matrix, with a large amount of embedded calcium hydroxide. The morphologies of C-S-H gel hydration produced in the three pictures of Figure 9 are obviously different. It is suggesting that inert or active ultrafine particles can promote cement hydration by providing a large surface area for the growth of cement hydration products [51-53]. The size effect of SMC fibers induces the microstructure formation of cement paste instead of reinforcing it. It is proposed that the primary role of the submicron-scale fibers is to provide potential heterogeneous nucleation sites for hydration reaction, due to the C-S-H gel growing on and along the surface of the SMC fibers until they are embedded inside of it. The final result is that independent C-S-H gel clusters are connected by SMC fibers, which makes the cement phase microstructure more uniform and compact, contributing to the increased strength and durability of cementitious composites.

\section{Conclusions}

Based on the obtained experimental results, the main results of this study are summarized as follows:

(1) SMC fibers can act as potential heterogeneous nucleation sites for the accumulation of hydration products. Hence, the addition of SMC accelerates the cement hydration rate during the early hydration period.

(2) Compared with SMC, MCC seems to retard the hydration of cement during the first $20 \mathrm{~h}$. The hydration heat flow of samples containing MCC is decreased by decreasing the water-to-cement ratio because of moisture absorption by the MCC. However, the 
hydration heat flow of the MCC sample increased after $20 \mathrm{~h}$ as the water stored in the MCC starts to participate in the hydration reaction. It can be inferred from the $\mathrm{CH}$ content obtained from the TG/DTG curves that SMC is more beneficial than MCC to improve the hydration process in later ages.

(3) Since the scale of SMC fibers and C-S-H gels match better than MCC fibers, it is estimated that the nucleation, induction, and bridging effects of SMC fibers make the cement paste microstructure more homogeneous and compact, but further research and advanced material characterization technology is needed to verify this hypothesis.

Author Contributions: J.W.: Conceptualization; Investigation; Methodology; Writing; Editing; Data Curation. Q.D.: Conceptualization; Investigation; Methodology. W.Y.: Conceptualization; Methodology; Software. L.W.: Conceptualization; Methodology. H.W.: Conceptualization; Methodology. All authors have read and agreed to the published version of the manuscript.

Funding: The authors would like to acknowledge the National Natural Science Foundation of China (No. 52078394), the Natural Science Foundation of Hubei Province (No. 2020CFB799), the Key Research and Development Program of Hubei Province (No. 2020BAB081).

Institutional Review Board Statement: Not applicable.

Informed Consent Statement: Not applicable.

Data Availability Statement: The data presented in this study are available on request from the corresponding author.

Acknowledgments: We thank members of our research group for stimulating discussions.

Conflicts of Interest: The authors declare no conflict of interest.

Sample Availability: Samples of the submicron fibrillated cellulose fiber are available from the authors.

\section{References}

1. Hansen, W. Report on early-age cracking: A summary of the latest document from ACI committee. Concr. Int. 2011, 33, 48-51.

2. Simon, K.M.; Kishen, J.C. A multiscale approach for modeling fatigue crack growth in concrete. Int. J. Fatigue 2017, 98, 1-13. [CrossRef]

3. Bentz, D.P.; Jensen, O.M.; Hansen, K.K.; Olesen, J.F.; Stang, H.; Haecker, C.-J. Influence of cement particle-size distribution on early age autogenous strains and stresses in cement-based materials. J. Am. Ceram. Soc. 2001, 84, 129-135. [CrossRef]

4. Brandt, A.M. Fibre reinforced cement-based (FRC) composites after over 40 years of development in building and civil engineering. Compos. Struct. 2008, 86, 3-9. [CrossRef]

5. Thomas, J.; Ramaswamy, A. Mechanical properties of steel fiber-reinforced concrete. J. Mater. Civ. Eng. 2007, 19, 385-392. [CrossRef]

6. Balouch, S.; Forth, J.; Granju, J.-L. Surface corrosion of steel fibre reinforced concrete. Cem. Concr. Res. 2010, 40, 410-414. [CrossRef]

7. Mukhopadhyay, S.; Khatana, S. A review on the use of fibers in reinforced cementitious concrete. J. Ind. Text. 2014, 45, 239-264. [CrossRef]

8. Katz, A.; Bentur, A. Mechanical properties and pore structure of carbon fiber reinforced cementitious composites. Cem. Concr. Res. 1994, 24, 214-220. [CrossRef]

9. Wang, Z.; Ma, G.; Ma, Z.; Zhang, Y. Flexural behavior of carbon fiber-reinforced concrete beams under impact loading. Cem. Concr. Compos. 2021, 118, 103910. [CrossRef]

10. Garces, P.; Fraile, J.; Vilaplana-Ortego, E.; Cazorla-Amoros, D.; Alcocel, E.; Andión, L. Effect of carbon fibres on the mechanical properties and corrosion levels of reinforced portland cement mortars. Cem. Concr. Res. 2005, 35, 324-331. [CrossRef]

11. Zheng, Q.; Chung, D. Carbon fiber reinforced cement composites improved by using chemical agents. Cem. Concr. Res. 1989, 19, 25-41. [CrossRef]

12. Yan, L.; Kasal, B.; Huang, L. A review of recent research on the use of cellulosic fibres, their fibre fabric reinforced cementitious, geo-polymer and polymer composites in civil engineering. Compos. Part B Eng. 2016, 92, 94-132. [CrossRef]

13. Cao, Y.; Tian, N.; Bahr, D.; Zavattieri, P.; Youngblood, J.; Moon, R.; Weiss, J. The influence of cellulose nanocrystals on the microstructure of cement paste. Cem. Concr. Compos. 2016, 74, 164-173. [CrossRef]

14. Ren, G.; Yao, B.; Huang, H.; Gao, X. Influence of sisal fibers on the mechanical performance of ultra-high performance concretes. Constr. Build. Mater. 2021, 286, 122958. [CrossRef] 
15. Li, Z.; Zhang, X.; Fa, C.; Zhang, Y.; Xiong, J.; Chen, H. Investigation on characteristics and properties of bagasse fibers: Performances of asphalt mixtures with bagasse fibers. Constr. Build. Mater. 2020, 248, 118648. [CrossRef]

16. Kundu, S.P.; Chakraborty, S.; Roy, A.; Adhikari, B.; Majumder, S.B. Chemically modified jute fibre reinforced non-pressure (NP) concrete pipes with improved mechanical properties. Constr. Build. Mater. 2012, 37, 841-850. [CrossRef]

17. Tolêdo Filho, R.D.; Scrivener, K.; England, G.L.; Ghavami, K. Durability of alkali-sensitive sisal and coconut fibres in cement mortar composites. Cem. Concr. Compos. 2000, 22, 127-143. [CrossRef]

18. Correia, V.D.C.; Santos, S.F.; Mármol, G.; Curvelo, A.A.D.S.; Savastano, H. Potential of bamboo organosolv pulp as a reinforcing element in fiber-cement materials. Constr. Build. Mater. 2014, 72, 65-71. [CrossRef]

19. Tonoli, G.; Santos, S.; Savastano, H.; Delvasto, S.; de Gutiérrez, R.M.; Murphy, M.D.M.L. Effects of natural weathering on microstructure and mineral composition of cementitious roofing tiles reinforced with fique fibre. Cem. Concr. Compos. 2011, 33, 225-232. [CrossRef]

20. Çomak, B.; Bideci, A.; Bideci, S. Effects of hemp fibers on characteristics of cement based mortar. Constr. Build. Mater. 2018, 169, 794-799. [CrossRef]

21. Sawsen, C.; Fouzia, K.; Mohamed, B.; Moussa, G. Optimizing the formulation of flax fiber-reinforced cement composites. Constr. Build. Mater. 2014, 54, 659-664. [CrossRef]

22. Onuaguluchi, O.; Banthia, N. Plant-based natural fibre reinforced cement composites: A review. Cem. Concr. Compos. 2016, 68, 96-108. [CrossRef]

23. Wei, J.; Meyer, C. Degradation mechanisms of natural fiber in the matrix of cement composites. Cem. Concr. Res. 2015, 73, 1-16. [CrossRef]

24. Ardanuy, M.; Claramunt, J.; García-Hortal, J.A.; Barra, M. Fiber-matrix interactions in cement mortar composites reinforced with cellulosic fibers. Cellulose 2011, 18, 281-289. [CrossRef]

25. Ardanuy, M.; Claramunt, J.; Filho, R.T. Cellulosic fiber reinforced cement-based composites: A review of recent research. Constr. Build. Mater. 2015, 79, 115-128. [CrossRef]

26. Aggarwal, L.K. Bagasse-reinforced cement compositese. Cem. Concr. Compos. 1995, 17, 107-112. [CrossRef]

27. Silva, F.D.A.; Mobasher, B.; Filho, R.T. Cracking mechanisms in durable sisal fiber reinforced cement composites. Cem. Concr. Compos. 2009, 31, 721-730. [CrossRef]

28. Trache, D.; Hussin, M.H.; Chuin, C.T.H.; Sabar, S.; Fazita, M.N.; Taiwo, O.; Hassan, T.M.; Haafiz, M.K.M. Microcrystalline cellulose: Isolation, characterization and bio-composites application-A review. Int. J. Biol. Macromol. 2016, 93, 789-804. [CrossRef]

29. Mali, P.; Sherje, A.P. Cellulose nanocrystals: Fundamentals and biomedical applications. Carbohydr. Polym. 2021, 118668. [CrossRef]

30. Hoyos, C.G.; Cristia, E.; Vázquez, A. Effect of cellulose microcrystalline particles on properties of cement based composites. Mater. Des. 2013, 51, 810-818. [CrossRef]

31. Barnat-Hunek, D.; Szymanska-Chargot, M.; Jarosz-Hadam, M.; Łagód, G. Effect of cellulose nanofibrils and nanocrystals on physical properties of concrete. Constr. Build. Mater. 2019, 223, 1-11. [CrossRef]

32. Takahashi, H.; Omori, S.; Asada, H.; Fukawa, H.; Gotoh, Y.; Morikawa, Y. Mechanical properties of cement-treated soil mixed with cellulose nanofibre. Appl. Sci. 2021, 11, 6425. [CrossRef]

33. Shama, P.; Rana, S.; Ferreira, S.; Filho, A.; Fangueiro, R. Ultrasonic dispersion of micro crystalline cellulose for developing cementitious composites with excellent strength and stiffness. Ind. Crop. Prod. 2018, 122, 156-165.

34. Lisboa, P.S.A.; Machado, M.D.S.; Brandes, R.; Hentges, T.I.; Vanin, D.V.F. The influence of microcrystalline cellulose on cement pastes early hydration modulus of rupture. Mater. Chem. Phys. 2021, 270, 124769. [CrossRef]

35. Fu, T.; Moon, R.J.; Zavattieri, P.; Youngblood, J.; Weiss, W.J. Cellulose nanomaterials as additives for cementitious materials. In Cellulose-Reinforced Nanofibre Composites; Jawaid, M., Boufi, S., Abdul Khalil, H.P.S., Eds.; Woodhead Publishing: Cambridge, UK, 2017; pp. 455-482.

36. De Siqueira, I.S.; Dweck, J.; Filho, R.D.T. Effect of microcrystalline and microfibrillated cellulose on the evolution of hydration of cement pastes by thermogravimetry. J. Therm. Anal. Calorim. 2020, 142, 1413-1428. [CrossRef]

37. Jiao, L.; Su, M.; Chen, L.; Wang, Y.; Zhu, H.; Dai, H. Natural cellulose nanofibers as sustainable enhancers in construction cement. PLoS ONE 2016, 11, e0168422. [CrossRef] [PubMed]

38. Boufi, S.; M’nif, A.; Khitouni, M.; Suñol, J.J.; Hammi, H.; Mejdoub, R. Nanofibrillated cellulose as nanoreinforcement in Portland cement: Thermal, mechanical and microstructural properties. J. Compos. Mater. 2017, 51, 2491-2503.

39. Goncalves, J.; Boluk, Y.; Bindiganavile, V. Cellulose nanofibres mitigate chloride ion ingress in cement-based systems. Cem. Concr. Compos. 2020, 114, 103780. [CrossRef]

40. Anju, T.; Ramamurthy, K.; Dhamodharan, R. Surface modified microcrystalline cellulose from cotton as a potential mineral admixture in cement mortar composite. Cem. Concr. Compos. 2016, 74, 147-153. [CrossRef]

41. Cao, Y.; Zavaterri, P.; Youngblood, J.; Moon, R.; Weiss, W. The influence of cellulose nanocrystal additions on the performance of cement paste. Cem. Concr. Compos. 2015, 56, 73-83. [CrossRef]

42. China National Standards. Method of Testing Cements—Determination of Strength; GB/T 17671-1999; China National Standards: Beijing, China, 1999.

43. Snellings, R.; Bazzoni, A.; Scrivener, K. The existence of amorphous phase in Portland cements: Physical factors affecting Rietveld quantitative phase analysis. Cem. Concr. Res. 2014, 59, 139-146. [CrossRef] 
44. Scrivener, K.L.; Juilland, P.; Monteiro, P.J. Advances in understanding hydration of Portland cement. Cem. Concr. Res. 2015, 78, 38-56. [CrossRef]

45. Bullard, J.W.; Jennings, H.M.; Livingston, R.; Nonat, A.; Scherer, G.; Schweitzer, J.S.; Scrivener, K.; Thomas, J. Mechanisms of cement hydration. Cem. Concr. Res. 2011, 41, 1208-1223. [CrossRef]

46. Quennoz, A.; Scrivener, K. Interactions between alite and C3A-gypsum hydrations in model cements. Cem. Concr. Res. 2013, 44, 46-54. [CrossRef]

47. Beck-Candanedo, S.; Roman, M.; Gray, D.G. Effect of reaction conditions on the properties and behavior of wood cellulose nanocrystal suspensions. Biomacromolecules 2005, 6, 1048-1054. [CrossRef]

48. Jain, J.; Neithalath, N. Analysis of calcium leaching behavior of plain and modified cement pastes in pure water. Cem. Concr. Compos. 2009, 31, 176-185. [CrossRef]

49. Ridi, F.; Fratini, E.; Baglioni, P. Cement: A two thousand year old nano-colloid. J. Colloid Interface Sci. 2011, 357, $255-264$. [CrossRef]

50. Lu, Z.; Kong, X.; Zhang, C.; Cai, Y. Effect of highly carboxylated colloidal polymers on cement hydration and interactions with calcium ions. Cem. Concr. Res. 2018, 113, 140-153. [CrossRef]

51. Xu, Z.; Zhou, Z.; Du, P.; Cheng, X. Effects of nano-limestone on hydration properties of tricalcium silicate. J. Therm. Anal. Calorim. 2017, 129, 75-83. [CrossRef]

52. Monasterio, M.; Gaitero, J.J.; Erkizia, E.; Bustos, A.G.; Miccio, L.A.; Dolado, J.S.; Cerveny, S. Effect of addition of silica- and amine functionalized silica-nanoparticles on the microstructure of calcium silicate hydrate (C-S-H) gel. J. Colloid Interface Sci. 2015, 450, 109-118. [CrossRef]

53. Hubler, M.H.; Thomas, J.J.; Jennings, H.M. Influence of nucleation seeding on the hydration kinetics and compressive strength of alkali activated slag paste. Cem. Concr. Res. 2011, 41, 842-846. [CrossRef] 